\title{
Improvement of HPMC Tablet Disintegration by the Addition of Inorganic Salts
}

\author{
Atsushi KaJYAMA, ${ }^{*, a}$ Hirokazu TAKAGI, ${ }^{a}$ Kunikazu Moribe, ${ }^{b}$ and Keiji Yamamoto ${ }^{b}$ \\ ${ }^{a}$ Pharmaceutical Research and Technology Labs., Astellas Pharma Inc.; 180 Ozumi, Yaizu 425-0072, Japan: and \\ ${ }^{b}$ Graduate School of Pharmaceutical Sciences, Chiba University; 1-33 Yayoi-cho, Inage-ku, Chiba 263-8522, Japan. \\ Received October 30, 2007; accepted January 28, 2008
}

Effects of inorganic salts on disintegration of hydroxypropylmethylcellulose (HPMC) matrix tablets have been studied. Adding disintegrants, such as Ac-di-sol $^{\circledR}$, Primojel ${ }^{\circledR}$, Kolidon-CL ${ }^{\circledR}$, or low substituted hydroxypropylcellulose (L-HPC ${ }^{\circledR}$ ) to HPMC matrix tablets had no effect on disintegration property. Disintegration time was improved by adding $\mathrm{NaHCO}_{3}, \mathrm{KH}_{2} \mathrm{PO}_{4}, \mathrm{~K}_{2} \mathrm{SO}_{4}, \mathrm{KCl}$, or $\mathrm{NaCl}$ to the $\mathrm{HPMC}$ tablets as tablet components. On the other hand, addition of $\mathrm{Na}_{2} \mathrm{CO}_{3}$, or $\mathrm{Na}_{2} \mathrm{SO}_{4}$ to the tablets showed no improvement of disintegration. The heat of dissolution of inorganic salts that improved disintegration of tablets was endothermic, while that of inorganic salts that did not improve disintegration of tablets was exothermic. These results suggested that the thermal environment and ionic strength inside the tablet might affect the disintegration of HPMC matrix tablets.

Key words hydroxypropylmethylcellulose; disintegration time; inorganic salt; dissolution enthalpy

The solid dispersion (SD) is known as a method to improve dissolution properties of poorly water soluble drugs. ${ }^{1-4)}$ Many pharmaceutical excipients are used as a carrier of SD, especially water soluble polymers such as hydroxypropylcellulose, chitosan, hydroxypropylmethylcellulose (HPMC) and polyvinylpyrrolidone due to their wide compatibilities with many drugs and the excellent stability. The SD powder prepared by using HPMC showed a fast dissolution of drug. However the dissolution rate of the drug from the tablet prepared from HPMC SD was very slow. Because HPMC formed a gel layer on the surface of tablet and interfered the tablet disintegration. There are many studies concerning about prolongation of dissolution of HPMC matrix tablet varying drug-HPMC ratio, viscosity grade of HPMC and combining of excipients. ${ }^{5-9)}$ While there are seldom reports about the acceleration of disintegration of HPMC tablets. Fagan et al. reported a catastrophic disintegration of HPMC matrix tablet in solution at different ionic strength. ${ }^{10}$ )

Generally, content of HPMC used is 1 to 5 times of drug content used for preparing solid dispersion. For one tablet, content of active pharmaceutical ingredient is usually 5$50 \%$ of total weight. Therefore, content of HPMC in one tablet has to be $5-50 \%$ of total weight.

Disintegration is the important step for drug release. ${ }^{11-13)}$ There are many factors affecting disintegration such as water uptake, dissolution of ingredients, swelling of disintegrants, deformation of granules, and heat of wetting. Therefore, no simple theory was satisfactorily applied to all disintegrant systems.

This study investigated the effect of various additives to the disintegration property of HPMC and lactose matrix tablets. The effect of inorganic salts on HPMC tablet disintegration was also explored.

\section{Experimental}

Materials Hydroxypropylmethylcellulose (TC-5E ${ }^{\circledR}$, Shin-Etsu Chemical), Ac-di-sol ${ }^{\mathbb{B}}$ (Asahi Chemical), Primojel ${ }^{\mathbb{B}}$ (Matsutani Chemical), Kolidon-CL ${ }^{\circledR}$ (BASF), low substituted hydroxypropylcellulose (L-HPC ${ }^{\circledR}$, ShinEtsu Chemical) used were of pharmaceutical manufacturing grade. The inorganic salts used were of reagent grade.

Preparation of Tablets Components of tablet were mixed in a mortar with a pestle. Then the mixture was compressed into tablet using an oil press or AutoGraph ${ }^{\circledR}$ (Shimadzu) with the punch of $7.5 \mathrm{~mm}$ diameter with $8 \mathrm{~mm}$ radius cup at $5000 \mathrm{kN} /$ punch pressure.

Determination of Disintegration Time Disintegration time was measured using the disintegration apparatus (Toyama Chemical, Japan). Measurement conditions were followed by the Japanese Pharmacopoeia XVI $\left(37^{\circ} \mathrm{C}\right.$, 30 strokes/min) without using disk. Aside from the disintegration test in salt solutions, the using test medium was distilled water.

Effect of HPMC Concentration on Tablet Disintegration Tablets were prepared using two components, lactose monohydrate and HPMC. Total weight of tablets was fixed as $150 \mathrm{mg}$. The HPMC concentrations in tablets were $0,5,10,20,33,67$ or $100 \%$ HPMC. Disintegration time was determined as described above $(n=3)$.

Effect of Disintegrants Tablets consisting of $50 \mathrm{mg}$ HPMC, $70 \mathrm{mg}$ lactose monohydrate and $30 \mathrm{mg}$ disintegrants $\left(\mathrm{Ac}-\mathrm{di}-\mathrm{sol}{ }^{\circledR}\right.$, Primojel $^{\circledR}$, Kolidon$\mathrm{CL}^{\circledR}, \mathrm{L}-\mathrm{HPC}^{\circledR}$, or $\mathrm{NaHCO}_{3}$ ) were prepared. As reference sample, tablets consisting of $50 \mathrm{mg}$ HPMC and $100 \mathrm{mg}$ lactose monohydrate were used. Disintegration time was measured for 3 tablets of each formulation.

Effect of Salt on Tablet Disintegration Tablets consisting of $50 \mathrm{mg}$ HPMC, $70 \mathrm{mg}$ lactose monohydrate and $30 \mathrm{mg}$ of inorganic salts were prepared for measurement of disintegration time $(n=3)$. Inorganic salts used were $\mathrm{NaHCO}_{3}, \mathrm{Na}_{2} \mathrm{CO}_{3}, \mathrm{Na}_{2} \mathrm{SO}_{4}, \mathrm{NaCl}, \mathrm{KCl}, \mathrm{KH}_{2} \mathrm{PO}_{4}$, and $\mathrm{K}_{2} \mathrm{SO}_{4}$.

Disintegration Test in Salt Solutions Disintegration tests were conducted using salt solutions $\left(\mathrm{NaHCO}_{3}, \mathrm{NaCl}, \mathrm{Na}_{2} \mathrm{SO}_{4}\right.$, or $\left.\mathrm{Na}_{2} \mathrm{CO}_{3}\right)$ with the ionic strength of 0.9 . The tested tablets were composed of $50 \mathrm{mg} \mathrm{HPMC}$ and $100 \mathrm{mg}$ lactose monohydrate.

Effect of Disintegration Medium Temperature on Tablet Disintegration To evaluate temperature effect on disintegration property, tablet disintegration time was measured under 4 different temperature conditions, $4^{\circ} \mathrm{C}$, $25^{\circ} \mathrm{C}, 37^{\circ} \mathrm{C}$, or $50^{\circ} \mathrm{C}$, using 3 kinds of formulation as follows:

(a) $50 \mathrm{mg}$ HPMC, $100 \mathrm{mg}$ lactose monohydrate

(b) $50 \mathrm{mg} \mathrm{HPMC}, 70 \mathrm{mg}$ lactose monohydrate, $30 \mathrm{mg} \mathrm{NaHCO}_{3}$

(c) $50 \mathrm{mg} \mathrm{HPMC}, 70 \mathrm{mg}$ lactose monohydrate, $30 \mathrm{mg} \mathrm{Na} \mathrm{CO}_{3}$

\section{Results and Discussion}

Disintegration of HPMC Matrix Tablets The correlation between HPMC content in tablets and disintegration time was investigated using tablet consisting of HPMC and lactose monohydrate. The results of disintegration tests are shown in Fig. 1. For the tablets including more than $10 \%$ HPMC, increasing concentration of HPMC caused an increase in disintegration time of HPMC tablets. When HPMC matrix tablets were exposed to water, HPMC absorbed water rapidly and formed gelatinous layer on the tablet surface. This result in undisintegrated tablet and the erosion became 


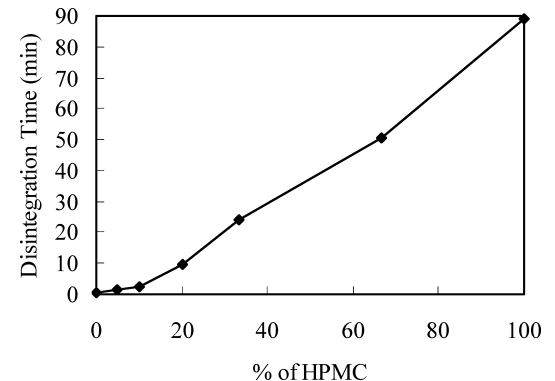

Fig. 1. Effect of HPMC Concentration on Tablet Disintegration Time

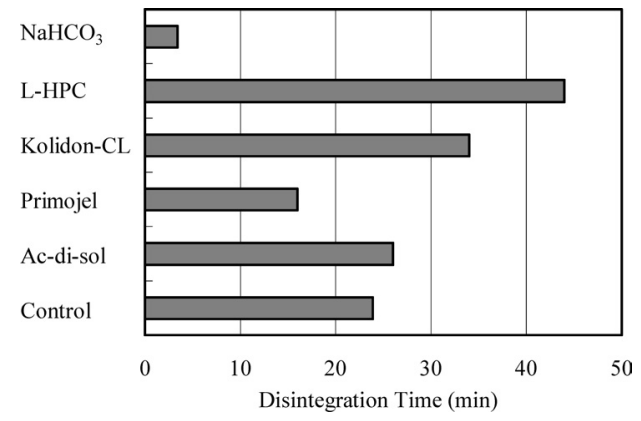

Fig. 2. Disintegration Time of HPMC Tablets Containing Various Disintegrants $(20 \%)$

the main path way for the size reduction of the tablet. ${ }^{5)}$ When the concentration of HPMC was less than $10 \%$, however, the gel layer of HPMC was not formed and the tablet could disintegrate.

Effect of Disintegrants on Disintegration Time of HPMC Matrix Tablets The disintegration time of HPMC matrix tablets including disintegrants $(20 \%$ in tablets) is displayed in Fig. 2. The concentration of HPMC was fixed at $33.3 \%$ (1/3 of tablet). There was no significant change in disintegration time by the addition of typical disintegrants such as Ac-di-sol ${ }^{\circledR}$, Primojel $^{\circledR}$, Kolidon-CL ${ }^{\circledR}$, L-HPC ${ }^{\circledR}$, although the addition of 1 to $10 \%$ disintegrant was usually enough to get rapid disintegration. In the HPMC matrix tablets, gel layer resisted the swelling of disintegrants and prevented from tablets disintegration. On the other hand, when $\mathrm{NaHCO}_{3}$ was added to the tablets, disintegration time was remarkably decreased. Sodium bicarbonate might interfere the forming of the HPMC gel layer.

Effect of Inorganic Salts on Tablet Disintegration From the results that $\mathrm{NaHCO}_{3}$ accelerated the disintegration of HPMC tablets, the effect of other sodium or potassium inorganic salts on the disintegration of HPMC tablets was examined (Fig. 3). The test sample tablets consisted of $50 \mathrm{mg}$ HPMC, $70 \mathrm{mg}$ lactose monohydrate and $30 \mathrm{mg}$ inorganic salt, while the control tablet contained $50 \mathrm{mg}$ HPMC and $100 \mathrm{mg}$ lactose monohydrate. Like $\mathrm{NaHCO}_{3}$, disintegration time was remarkably improved by adding $\mathrm{KH}_{2} \mathrm{PO}_{4}, \mathrm{~K}_{2} \mathrm{SO}_{4}, \mathrm{KCl}$, and $\mathrm{NaCl}$. However, there was no significant improvement of disintegration time in the cases of $\mathrm{Na}_{2} \mathrm{CO}_{3}$, and $\mathrm{Na}_{2} \mathrm{SO}_{4}$. Especially by the addition of $\mathrm{Na}_{2} \mathrm{CO}_{3}$, disintegration time was obviously prolonged compared with the control tablet. From these results, it was found that there was no relationship between ion series of inorganic salts and disintegration time.

Disintegration Test in Salt Solutions To clarify the mechanism of accelerated disintegration of inorganic salts,

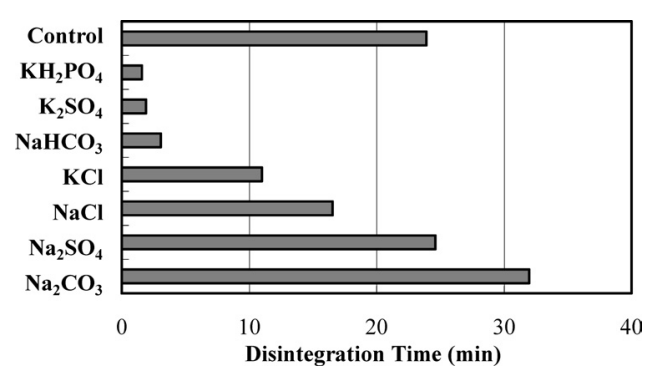

Fig. 3. Disintegration Time of HPMC Tablets Containing Various Inorganic Salts $(20 \%)$

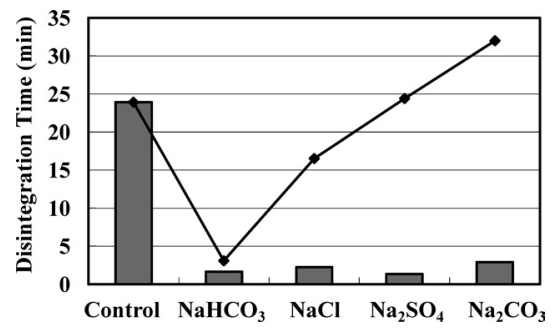

Fig. 4. Effect of Inorganic Salts Solution on Disintegration Time of Lactose and HPMC Tablets

Bars: disintegration time of lactose/HPMC tablets in salt solutions, line: disintegration time of tablets containing salts in water.

each salt was added into disintegration medium instead of adding into tablet. The disintegration tests were conducted using control tablets consisting of $50 \mathrm{mg}$ HPMC and $100 \mathrm{mg}$ lactose monohydrate. The ionic strength of the salt solution was adjusted to 0.9 since salting out effect was related to the ionic strength. The results are shown in Fig. 4. Rapid tablet disintegration was clearly observed in all salt solutions compared with the control and there was no difference among salts (bars in Fig. 4). While there was wide distribution of disintegration time when different salts were added to the tablets (lines in Fig. 4).

Mitchell et al. reported the effect of salts on the dissolution of propranolol from HPMC matrix tablets. ${ }^{14)}$ The HPMC matrix tablets in the certain concentration of salts solution started to disintegrate before the gel which normally protects the inner constituents from dissolution was formed. Fagan et $a l$. also introduced a concept of threshold ionic strengths that catastrophic disintegration (within $15 \mathrm{~min}$ ) occurred when the salt concentration in the disintegration fluid approached the cloud-point of hydroxyalkylcellulose. ${ }^{10)}$ When $\mathrm{NaHCO}_{3}$ and $\mathrm{Na}_{2} \mathrm{CO}_{3}$ were added into tablets or into dissolution media, however, different effects on disintegration time were observed. This difference between $\mathrm{NaHCO}_{3}$ and $\mathrm{Na}_{2} \mathrm{CO}_{3}$ should not come from ion series, but from some factors in the dissolution process of the salts.

Correlation with Dissolution Enthalpy To discuss the factors in salt dissolution process that might affect tablet disintegration, the solubility and the heat of dissolution of salts are presented in Table 1. There was no correlation between disintegration time and solubility $\left(R^{2}=0.54\right)$. On the other hand, there was a linear correlation between disintegration time and heat of dissolution as shown in Fig. $5\left(R^{2}=0.91\right)$. However, since the same weight $(30 \mathrm{mg})$ of salts was added in all samples, so the heat of dissolution should be normalized by the weight of salt added. As the acceleration of tablet 
Table 1. Various Properties of Inorganic Salts and Disintegration Time

\begin{tabular}{lccc}
\hline \hline \multicolumn{1}{c}{ Salt } & $\begin{array}{c}\text { Solubility at } \\
30^{\circ} \mathrm{C}^{a)} \\
(\mathrm{g} / \mathrm{l})\end{array}$ & $\begin{array}{c}\text { Heat of dissolution } \\
\text { enthalpy } \\
(\mathrm{kJ} / \mathrm{mol})\end{array}$ & $\begin{array}{c}\text { Disinegration } \\
\text { time } \\
(\mathrm{min})\end{array}$ \\
\hline $\mathrm{NaHCO}_{3}$ & 127 & 19.1 & 3.13 \\
$\mathrm{KH}_{2} \mathrm{PO}_{4}$ & 200 & 19.6 & 1.73 \\
$\mathrm{~K}_{2} \mathrm{SO}_{4}$ & 148 & 23.7 & 2.12 \\
$\mathrm{KCl}$ & 401 & 17.2 & 11.7 \\
$\mathrm{NaCl}$ & 363 & 3.90 & 16.5 \\
$\mathrm{Na}_{2} \mathrm{SO}_{4}$ & 482 & -2.40 & 24.6 \\
$\mathrm{Na}_{2} \mathrm{CO}_{3}$ & 328 & -26.7 & 32.0 \\
\hline
\end{tabular}

a) The Chemical Society of Japan, "Kagakubinran kiso-hen," Maruzen, 2004.

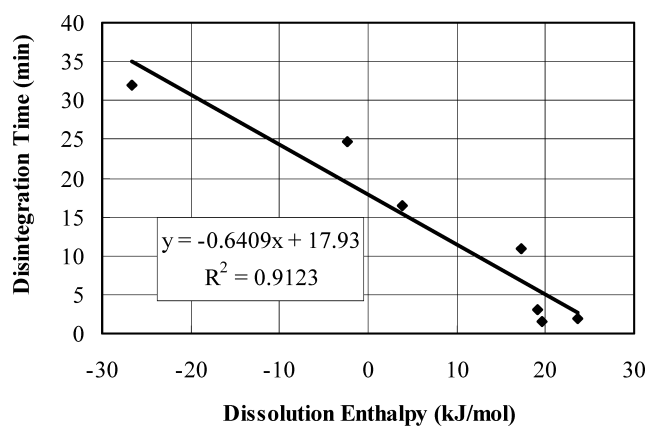

Fig. 5. Relationship between Heat of Dissolution Enthalpy and Tablet Disintegration Time

disintegration should be due to salting out effect, the effect was related to ionic strength. Then, the heat of dissolution of salt was recalculated based on ionic strength (Fig. 6).

When inorganic salts were added into dissolution media, the ionic strength, $I$, was calculated according to Eq. 1;

$$
I=0.5 \sum\left(m Z^{2}\right)
$$

where $m$ is molarity, and $Z$ is the valency of each ion in the solution.

In the case of the addition of inorganic salts into tablet, inorganic salts were dissolved and diluted with water penetrated into the tablet. Since the diluted salts were subsequently released from the tablet, the ionic strength of the tablet inside was not constant. Therefore, assuming that the fluid volume in tablet stays constant, multiplying dissolution enthalpy by the ionic strength per unit volume was performed to consider both the dissolution enthalpy and the ionic strength effects on the tablet disintegration time.

Fagan et al. ${ }^{10)}$ and Mitchell et al. ${ }^{14)}$ reported that HPMC matrix tablet was rapidly disintegrated in the dissolution fluid when the ionic strength of the fluid exceeded at critical value. Johnson et al. ${ }^{15)}$ also reported that the influence of ionic strength in the dissolution fluid on matrix tablets of hydroxypropyl cellulose. The matrix tablets swelled and gelated in dissolution water without any disruption of the matrix integrity at ionic strengths less than 0.5 . On the other hand, hydroxypropyl cellulose tablets were disintegrated at ionic strengths $0.5-1.0$ of $\mathrm{NaCl}$ solution. When inorganic salts were added into the tablet, the salts in tablets were dissolved with penetrated water and became high concentrated ionic solution in the tablet. The tablet disintegration might be accelerated by this high concentrated ionic solution.

The salts that had positive dissolution enthalpy could ac-

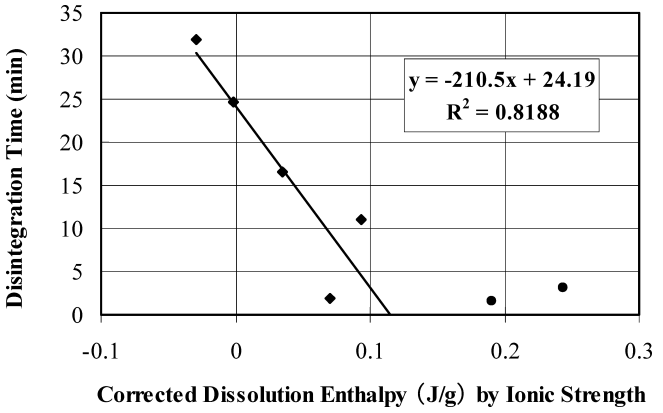

Fig. 6. Relationship between Tablet Disintegration Time and Heat of Dissolution Enthalpy after Correction of Ionic Strength of Inorganic Salts in Tablets

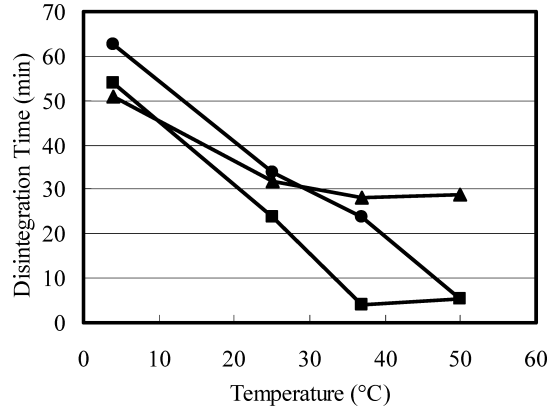

Fig. 7. Effect of Solution Temperature on Disintegration Time

๑, HPMC : lactose; $\mathbf{\square}, \mathrm{HPMC}$ : lactose : $\mathrm{NaHCO}_{3} ; \boldsymbol{\Delta}, \mathrm{HPMC}$ : lactose : $\mathrm{Na}_{2} \mathrm{CO}_{3}$.

celerate the disintegration of tablets and the salts that had negative dissolution enthalpy prolonged the disintegration time of tablets. This suggests that the thermal environment and ionic strength inside the tablet might affect the disintegration of tablets.

Effect of Temperature of Disintegration Medium on Tablet Disintegration As the heat of dissolution was correlated with tablet disintegration property, effect of temperature of disintegration medium on tablet disintegration was investigated by changing medium temperature $4,25,37$, and $50^{\circ} \mathrm{C}$

Effects of medium temperature on the disintegration time are shown in Fig. 7. The disintegration time of control tablets became shorter with the increase of medium temperature. This was explained in terms of the increase in solubility of lactose monohydrate by temperature. Tablets containing $\mathrm{NaHCO}_{3}$ showed shorter disintegration time compared with the control tablets except at $50^{\circ} \mathrm{C}$. Especially, clear disintegration improvement effect was observed at $37^{\circ} \mathrm{C}$. Tablets containing $\mathrm{Na}_{2} \mathrm{CO}_{3}$ showed rapid disintegration at $4{ }^{\circ} \mathrm{C}$ compare with control tablets. Disintegration time was not depended on the temperature between $25^{\circ} \mathrm{C}$ and $50^{\circ} \mathrm{C}$. Compared with control tablets, disintegration time was prolonged at $50^{\circ} \mathrm{C}$.

By visual inspection, quick disintegration of control tablets and tablets containing $\mathrm{NaHCO}_{3}$ were observed at $50{ }^{\circ} \mathrm{C}$. However, on the surface of $\mathrm{Na}_{2} \mathrm{CO}_{3}$ tablets, gel layer was formed at $50{ }^{\circ} \mathrm{C}$, then gradual erosion from the surface. This suggests that $\mathrm{Na}_{2} \mathrm{CO}_{3}$ promote a gel forming function of HPMC.

Sarker et al. reported hydration-dehydration properties of HPMC ${ }^{16)}$ As the temperature is increased, polymer mole- 
cules lose their water of hydration. When the temperature is higher than the lower critical solution temperature (LCST), the hydrophobic bonding will be formed. Therefore, the gel layer forming of $\mathrm{Na}_{2} \mathrm{CO}_{3}$ tablets at $50{ }^{\circ} \mathrm{C}$ could be explained by this thermal gelation.

\section{Conclusions}

The HPMC matrix tablets dissolved or disintegrated slowly because of the gel layer formation on the surface of the tablet. Disintegration of tablets containing HPMC was not improved by using typical disintegrants, but it could be improved by the addition of some kinds of inorganic salts that had positive heat of dissolution. On the other hand, salts that had negative dissolution enthalpy prolonged disintegration of tablet. These suggest that the thermal environment and ionic strength inside the tablet might be a key factor for the disintegration of HPMC matrix tablets.

\section{References}

1) Rasenack N., Mueller B. W., Pharm. Ind., 67, 583-591 (2005).

2) Craig D. Q. M., Int. J. Pharm., 231, 131-144 (2002).
3) Serajuddin A. T., J. Pharm. Sci., 88, 1058-1066 (1999).

4) Yano K., Kajiyama A., Yamazaki S., Matsumura Y., Watanabe K., Yamamoto K., Chem. Pharm. Bull., 44, 2309-2312 (1996).

5) Miranda A., Millan M., Caraballo I., Int. J. Pharm., 311, 75-81 (2006).

6) Fu X. C., Wang G. P., Liang W. Q., Chow M. S. S., J. Controlled Release, 95, 209-216 (2004).

7) Siepmann J., Peppas N. A., Adv. Drug Deliv. Rev., 48, 139-157 (2001).

8) Velasco M. V., Ford J. L., Rowe P., Rajabi-Siahboomi A. R., J. Controlled Release, 57, 75-85 (1999).

9) Xu G., Sunada H., Chem. Pharm. Bull., 43, 483-487 (1995).

10) Fagan P. G., Harrison P. J., Shankland N., J. Pharm. Pharmacol., 41, 25P (1989).

11) Carstensen J. T., “Advanced Pharmaceutical Solids," Marcel Dekker Inc., New York, 2001, pp. 427-428.

12) Caramella C., Colombo P., Conte U., La Manna A., Drug Dev. Ind. Pharm., 13, 2111-2145 (1987).

13) Kanig J., Rudnic E. M., Pharm. Tech., 1984, 50-63 (1984).

14) Mitchell K., Ford J. L., Armstrong D. J., Elliott P. N. C., Rostron C., Hogan J. E., Int. J. Pharm., 66, 233-242 (1990).

15) Johnson J. L., Holinej J., Williams M. D., Int. J. Pharm., 90, 151-159 (1993).

16) Sarker N., Walker L. C., Carbohydr. Polym., 27, 177-185 (1995). 